\title{
ATRIBUIÇÃO PELOS OUTROS: DISCUTINDO AS CATEGORIAS "CABOCLO" E "MULATA" ATRAVÉS DAS CONTRIBUIÇÕES DE LÉLIA GONZALEZ E CARMEM IZABEL RODRIGUES
}

JADE NEVES MOREIRA ${ }^{1}$

UFPA, BRASIL

https://orcid.org/0000-0002-0075-2347

\section{RESENHA}

GONZÁLEZ, Lélia. Racismo e sexismo na cultura brasileira. Revista Ciências Sociais Hoje, São Paulo, 1984, p. 223-244.

RODRIGUES, Carmen Izabel. Caboclos na Amazônia: a identidade na diferença. Revista Novos Cadernos NAEA, v. 9, n. 1, p. 119-130, jun. 2006.

O processo de colonização do Brasil, sustentado pelo sistema de escravidão, imprimiu marcas profundas e duradouras na estrutura da sociedade nacional, seja no âmbito das relações concretas ou no imaginário da população.

É certo que, mesmo após a abolição legal do trabalho escravo, as classes dominantes encarregaram-se de perpetuar, de outras formas, a exploração dos grupos étnico-raciais subalternos. Nesse sentido, pretos e ameríndios foram forçados a viver em condições de intensa vulnerabilidade social, desde as péssimas condições de moradia, saúde

\footnotetext{
${ }^{1}$ Mestranda do Programa de Pós-Graduação em Ciência Política da Universidade Federal do Pará. E-mail: jade.nevesmoreira@gmail.com

MOREIRA, Jade Neves. Atribuição pelos outros: discutindo as categorias "caboclo" e "mulata" através das contribuições de Lélia Gonzalez e Carmem Izabel Rodrigues. Espaço Ameríndio, Porto Alegre, v. 15, n. 2, p. 316-319, mai./ago. 2021.
} 
pública, educação até os estigmas geradores de diversos tipos de violência física e simbólica. Ainda na contemporaneidade, este é o cenário que configura a dinâmica das relações sociais no país.

Com a finalidade de escamotear o contexto de desigualdades - e, juntamente, retirar do debate público a necessidade de se promover políticas sociais voltadas para a garantia dos direitos das populações negra e indígena -, instituições de governo, meios de comunicação e teóricos acadêmicos empregaram esforços no sentido de criar uma imagem da sociedade brasileira em que não houvesse qualquer tipo de conflito ou discriminação.

O chamado mito da democracia racial surge, então, na primeira metade do século XX com a função de ocultar, através da celebração à mestiçagem, o uso social da categoria raça como mecanismo de exclusão. O caráter ambíguo desta construção de pensamento se encontra no fato de que ela atribui valor à mestiçagem como forma de negar o racismo e as disparidades sociais, ao mesmo tempo em que também aprisiona o "mestiço" no lugar da subalternidade.

Para a reflexão que se propõe aqui, interessa frisar que a eficácia simbólica conquistada pelo mito da democracia racial se expressa em categorias fortemente incorporadas à linguagem nacional, como a do "caboclo" e da "mulata". O emprego dessas denominações dissolve as identidades étnico-raciais de grupos dominados na medida em que os afasta de suas origens históricas e institui a noção de que, no Brasil, todos pertenceriam a uma raça mista e de que não haveria um sistema de desigualdades baseado em diferenças fenotípicas. Assim, a mestiçagem seria um resultado natural dos processos de formação da nação, cujo caráter violento e arquitetado é igualmente apagado pela ideologia da democracia racial.

Pode-se dizer que, em ambos os casos, trata-se daquilo que Carmen Izabel Rodrigues (2006) afirma ao analisar a ideia de "caboclo" enquanto "uma categoria de atribuição pelos outros e não de auto-atribuição, uma categoria de acusação e não de reconhecimento de direitos e prerrogativas, [...] marcada por ausências, por uma espécie de invisibilidade que mais nega que afirma" (RODRIGUES, 2006, p. 121). Essa questão também é levantada por Lélia González (1984) quando aponta que a lógica da dominação visa domesticar e infantilizar o negro, que é sistematicamente objeto de falas externas. Ou seja, "é aquele que não tem fala própria, é a criança que se fala na terceira pessoa, porque falada pelos adultos" (GONZÁLEZ, 1984, p. 225).

Ambas as autoras demonstram o sentido pejorativo das classificações "caboclo" e "mulata" e sua origem em estereótipos diversos, que agregam desde a dimensão racial até as dimensões geográfica e sexual. O caboclo - categoria amplamente evocada na região amazônica - seria o trabalhador rural, de ascendência indígena, habitante dos interiores, um indivíduo de cultura inferior à cultura do locutor e que está apartado da sociedade moderna.

Esta denominação apresenta também um outro lado - que se pode dizer carregado de misticismos - em que "o caboclo é visto como o guardião da floresta, aquele que detém os saberes nativos sobre a região. MOREIRA, Jade Neves. Atribuição pelos outros: discutindo as categorias "caboclo" e "mulata" através das contribuições de Lélia Gonzalez e Carmem Izabel Rodrigues. Espaço Ameríndio, Porto Alegre, v. 15, n. 2, p. 316-319, mai./ago. 2021. 
Neste contexto o caboclo é reconstituído como originário do lugar, herdeiro dos antepassados indígenas e totalmente adaptado à natureza" (RODRIGUES, 2006, p. 124).

Muito embora seja um termo notadamente complexo e ambíguo, estes são seus usos mais recorrentes, de maneira que não se pode associá-lo a qualquer grupo específico. Nesse aspecto, predomina seu caráter relacional, o que implica dizer que o caboclo é aquele que não compartilha dos atributos da civilização branca e urbana.

A mulata, por sua vez, é definida, sobretudo, pela sexualização. Lélia González traz à tona os festejos de carnaval e defende ser essa a ocasião em que o mito da democracia racial é "atualizado com toda sua força simbólica" (GONZÁLEZ, 1984, p. 228). Os ritos carnavalescos tiram a mulher negra do anonimato para coloca-la em um lugar de objetificação, e sua presença nos desfiles das escolas de samba suscita comentários que exaltam seu corpo e sua dança. Assim, a construção acerca da mulata seria a de uma mulher de ascendência africana, formas corporais avantajadas e comportamento provocativo.

Ainda que a figura da mulata seja comumente enaltecida como símbolo de um fenótipo tipicamente brasileiro, ocorre aí uma falsa valorização da mulher negra, para quem a igualdade social e política não é uma realidade. Além disso, no cotidiano, a mulata permanece estruturalmente associada à condição de serviçal, assumindo a função de empregada doméstica (que integra o lugar social atribuído historicamente às mulheres negras).

Ser falado pelo outro é uma das grandes implicações do racismo. Com isso, a subjugação de grupos marginalizados atravessa também - e muito fortemente - a linguagem, uma vez que ela é um dos principais canais por meio dos quais os indivíduos e grupos exprimem sua maneira de ver o mundo e de classificar os demais. Nesse caso, a linguagem reforça a supremacia da raça branca, retirando de negros e indígenas a possibilidade de falar por si mesmos e se autodenominar.

Os conceitos em discussão se manifestam no campo da consciência, o qual está dialeticamente relacionado com o campo da memória. Segundo González, o primeiro "é o lugar da rejeição, consciência se expressa como discurso dominante (ou efeitos desse discurso) numa dada cultura, ocultando memória, mediante a imposição do que ela, consciência, afirma como a verdade" (GONZÁLEZ, 1984, p. 226). Portanto, é precisamente a memória - o lugar em que se inscreve a história de indivíduos e grupos - que o racismo, sob a conformação do mito da democracia racial, desvaloriza e invisibiliza.

Ainda, Rodrigues insiste que a categoria "caboclo" está vinculada a um "lugar de representação" (RODRIGUES, 2006, p. 126). Este seria um lugar residual, uma fronteira móvel constituída pela negação. A cultura cabocla não existe como cultura própria, ela é aquilo que foi excluído do universo da modernidade e que, por essa razão, não é válida.

Esse sistema de atribuições se traduz na tentativa de impedir o reconhecimento das desigualdades sociais que decorrem da dominação pela raça, pela classe e também pelo gênero. Negar a multiplicidade das identidades e culturas que integram a sociedade brasileira através da MOREIRA, Jade Neves. Atribuição pelos outros: discutindo as categorias "caboclo" e "mulata" através das contribuições de Lélia Gonzalez e Carmem Izabel Rodrigues. Espaço Ameríndio, Porto Alegre, v. 15, n. 2, p. 316-319, mai./ago. 2021. 
imposição de categorias que evitam referir-se diretamente à África e às populações ameríndias retira desses indivíduos o papel de sujeitos ativos de uma história legítima. Obstruir a unidade de grupos marginalizados permite tolher sua articulação política em prol de direitos e reparação social pela exploração sofrida.

A ideia de que a mestiçagem teria consumado os conflitos raciais no Brasil, ligada à falsa valorização - impregnada de estereótipos, como a sexualização da mulata e a mistificação do caboclo -, cria para os descendentes das populações africanas e ameríndias um limbo, um lugar de indefinição e esquecimento em que é necessário autoconstruir-se no jogo da diferença.

Conquanto a apropriação do termo "caboclo" por uma parcela da população amazônica denote um movimento de resistência a um processo aniquilador da cultura e identidade locais, o mesmo não parece ocorrer em relação à mulata. Esta construção continua a produzir consequências violentas e destrutivas para as mulheres negras, pois longe de permitir um resgate político de sua comunidade e de sua identidade étnica e cultural, o conceito as empurra para baixo na hierarquia das relações sociais, reduzindo-as a um corpo a ser admirado/violentado.

De fato, as implicações desse processo são muito mais profundas e complexas do que esta breve reflexão permite antever. Então, para concluir - mas sem dar por encerrado o debate -, vale a pena retomar as notáveis palavras de Lélia González:

"Branqueamento, não importa em que nível, é o que a consciência cobra da gente, prá mal aceitar a presença da gente, prá mal aceitar a presença da gente" (GONZÁLEZ, 1984, p. 227).

Recebido em: 27/01/2021 * Aprovado em: 19/07/2021 * Publicado em: 30/08/2021

MOREIRA, Jade Neves. Atribuição pelos outros: discutindo as categorias "caboclo" e "mulata" através das contribuições de Lélia Gonzalez e Carmem Izabel Rodrigues. Espaço Ameríndio, Porto Alegre, v. 15, n. 2, p. 316-319, mai./ago. 2021. 